\title{
Covid-19: Two thirds of healthcare workers who have died were from ethnic minorities
}

\section{Abi Rimmer}

The BMJ

Two thirds of healthcare workers who have died from covid-19 were from an ethnic minority background, and at least half were not born in the UK, researchers have found.

Tim Cook, professor of anaesthesia at the Royal United Hospital Bath and the University of Bristol, and colleagues looked at the deaths of 106 healthcare workers, $63 \%$ of whom were from an ethnic minority background, and they reported their findings in the Health Service Journal. ${ }^{1}$

Eighteen of the 19 doctors and dentists who have died from covid-19 were from ethnic minority backgrounds. The same was true of $71 \%$ of the 35 nurses and midwives who have died, $56 \%$ of the 27 healthcare support workers who have died, and $29 \%$ of the 25 other staff who have died.

The causes of this excess mortality is not clear and could be biological, medical, or sociological, said the researchers, who highlighted the need for a concerted effort to seek explanations and solutions.

The team also found that "a minimum of $56(53 \%)$ of those healthcare workers who died were not born in this country." They called for the government's inquiry into the deaths ${ }^{2}$ of ethnic minority healthcare workers to also look at staff who had migrated to the UK.

\section{PPE practices}

A notable absence of deaths occurred among certain staff groups, the researchers said. Among the doctors, for example, the specialties where deaths occurred were surgery (five cases), general practice (four), emergency medicine (two), and one death each in histopathology, geriatrics, neurorehabilitation, paediatrics, and psychiatry. No anaesthetists or intensivists were identified as having died.

The reason for these groups being absent from the data was unknown, the researchers said, but it could partly be because of the rigorous use of personal protective equipment (PPE) and the associated practices among staff in these specialties.

"It may be that this rigour is protecting staff better than some fear and the results can be considered cautiously reassuring," the researchers said. "However, this finding is not a reason to slacken off on the appropriately rigorous use of PPE, but rather to wonder why others, who are likely involved in what are generally considered to be lower risk activities, are becoming infected and consider whether wider use of rigorous PPE is indicated."

They noted numerous limitations to their dataset and called for a central registry of deaths among health and social care workers. This would help to "establish facts, enable robust rapid analysis and to explore whether social or employment inequalities are impacting on the rates of infection of these staff during the conduct of their duties and causing avoidable deaths."

\section{\#properPPE}

The BMJ's \#properPPE campaign is calling for healthcare workers on the front line to be given the appropriate level of PPE. We are calling for doctors to have the correct PPE for each clinical setting, for PPE of sufficient quality and quantity, and for doctors to be given what they need to make them feel safe.

Share your stories with us on social media by using \#properPPE or by email at newsdesk@bmj.com. We want to hear about experiences so that we can push governments to act.

1 Cook T, Kursumovic E, Lennane S. Exclusive: deaths of NHS staff from covid-19 analysed. Health Serv J 2020 Apr 22. https://www.hsj.co.uk/exclusive-deaths-of-nhs-staff-fromcovid-19-analysed/7027471. article.

2 Rimmer A. Covid-19: Disproportionate impact on ethnic minority healthcare workers will be explored by government. BMJ 2020;369:m1562. 10.1136/bmj.m1562 32303494 Published by the BMJ Publishing Group Limited. For permission to use (where not already granted under a licence) please go to http://group.bmj.com/group/rights-licensing/ permissions 